\title{
Интерферометрическое исследование сверхзвуковой газовой мишени для лазерного ускорения электронов
}

\author{
С.А. Бычкова \\ Новосибирский государственный технический университет \\ Институт лазерной физики СО РАН \\ E-mail: sonya.bychkova@mail.ru
}

DOI: 10.31868/RFL2020.216-217

В последние десятилетия ведется активное исследование различных режимов кильватерного ускорения электронов, что обусловлено перспективами создания ускорителей электронов нового поколения, более компактных и менее затратных по сравнению с традиционными линейными и циклическими ускорителями [1,2]. В ИЛФ $\mathrm{CO} \mathrm{PAH}$, в лаборатории физики лазеров сверхкоротких импульсов создается установка для лазерно-кильватерного ускорения электронов. Для процесса ускорения частиц необходимо контролировать параметры струи газа и лазерного излучения [3]. Поэтому распределение плотности газа в сверхзвуковой струе необходимо измерять с высокой точностью, обычно для этого используется интерферометрический способ. В данной работе анализируется точность интерферометрических измерений плотности газа интерферометрами Маха - Цендера и с бипризмой Френеля, сравниваются методы восстановления распределений плотности из интерферограмм, представлено интерферометрическое исследование и анализ характеристик сверхзвуковых струй азота, генерируемых двумя соплами Лаваля с разными критическими сечениями.

Звуковая струя азота создавалась звуковым соплом, помещенным в вакуумную камеру. Вакуумную камеру откачивали до $10^{-3}$ мбар. Сопло работало в импульсном режиме. CCD-камера регистрировала интерференционную картину и была синхронизована с клапаном. Импульсная струя работала под давлением 10 бар. Источником света для интерферометра служил Nd:YAG лазер непрерывного режима с длиной волны 532 нм и мощностью 100 мВт.

Восстановление фазовой картины струи выполнялось по двум интерферограммам: струи и фона, с использованием методов прямого и обратного преобразований Фурье для выделения фазовых искажений. Затем из восстановленной фазовой картины восстанавливалось распределения плотности газа в струе двумя способами: 1) с применением обратного преобразование Абеля и 2) с разложением радиальных распределений плотности по гипергауссовым функциям [3].

Для обработки интерферограмм, использовалась программа, написанная на языке программирования python.

Исследования интерферограмм сверхзвуковых и звуковых струй азота показали, что звуковые колебания, которым подвержен интерферометр МахаЦендера, отсутствуют в интерферометре с бипризмой. Поэтому точность и воспроизводимость восстановления фазовой картины объекта в последнем случае возрастают. Сравнив два метода восстановления плотности газа в струе, выяснили, что методы, в пределах допустимой погрешности, дают одинаковый результат. Метод с разложением радиальных распределений плотности по гипергауссовым функциям позволяет получить полностью симметричное 
распределение плотности газа осесимметричного объекта - струи. Исследовались сверхзвуковые струи азота, формируемые сверхзвуковыми соплами Лаваля с выходными диаметрами 1.5 и 1.7 мм, критическими диаметрами $d_{c r} 350$ и 750 мкм и углом раствора $14^{\circ}$. Изучение радиальных распределений плотности газа в сверхзвуковых струях (рис. 1.) показало, что струя, генерируемая соплом Лаваля с $d_{c r}=750$ мкм, в центральной области которой распределение плотности газа почти не меняется, лучше подходит в качестве мишени для изучения лазерного ускорения частиц.

a)

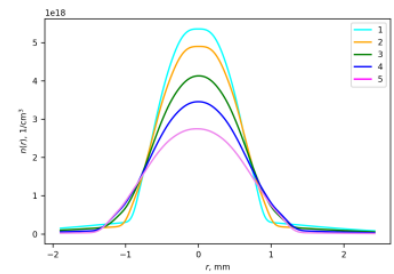

b)

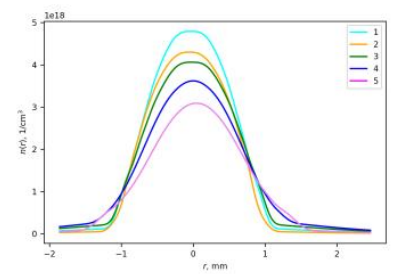

Рис. 1. Радиальные распределения плотности газа в сверхзвуковой струе на различных расстояниях от выхода сопел Лаваля с $d_{c r}=350$ мкм (a) и $d_{c r}=750$ мкм (b); расстояние от поверхности сопла (мм): $1-0,2$ $0.32,3-0.64,4-0.97,5-1.29$.

\section{Литература}

[1] E. Esarey, C. B. Schroeder, W. P. Leemans, Rev. Mod. Phys. 81, 1229-1285 (2009).

[2] F. Albert, A. G. R. Thomas, S. P. D. Mangles et al., PPCF56, 084015 (2014).

[3] S.V. Avtaeva, K.V. Gubin,V.I. Trunov, P.V. Tuev, JOSA A, 36(5), pp. 910-917 (2019).

Научный руководитель - док. физ.-мат. наук С.В. Автаева 